\title{
MiniTab in Assessment of the Dynamics Course
}

\author{
Zhongming Liang \\ Purdue University Fort Wayne
}

\begin{abstract}
For better interpretation of assessment data, the author uses MiniTab, a statistical analysis software package, for evaluating students' learning outcomes with multiple statistical measures in several his courses in the Mechanical Engineering Technology (MET) program, such as the dynamics course discussed in this paper as an example. The better assessment and follow-up actions have indeed led to improvement of students' learning and satisfaction. Expected course learning outcome, assessment tools, statistical analysis in assessment process, assessment-based actions for improvement and improvement results are discussed in the body of the paper.
\end{abstract}

\section{Introduction}

To meet the ABET requirements ${ }^{1}$ and the university requirements ${ }^{2}$, assessment is performed on each course. The author of this paper uses MiniTab, a statistics tool, to evaluate students' learning outcomes with multiple statistical measures for each of his courses and uses the assessment results to define actions for continuous improvement. The actions have indeed led to improvement of students' learning and satisfaction. Since the dynamics course has always been a difficult one for the students, it is used for discussion in this paper.

The paper is organized as follows. First, we list the course learning outcomes and show the assessment tool matrix of the learning outcomes. Then we discuss assessment with statistical analysis. The statistical analysis goes beyond normally used statistical measures for assessment such as the mean, the median and the standard deviation of collected data. Therefore more useful information can be extracted for continuous improvement. The assessment and statistical analysis are supplemented by a survey of students' perception of their learning. Finally we discuss actions as suggested by the assessment results and learning outcomes improvement resulting from the actions

\section{Defining course learning outcomes}

This section is an integral part of the paper. Course learning outcomes are defined to serve the program learning outcomes. The syllabus of the dynamics course has these: 
Course Learning Outcomes (The letters in the parenthesis of each outcome refer to the relevant MET program outcomes. Information about MET program outcomes is at http://www.miet.ipfw.edu/):

The student is expected to demonstrate the following learning outcomes:

1. Knowledge of particle kinematics and its applications in mechanical analysis (a1, $\mathrm{f}, \mathrm{k})$

2. Knowledge of particle kinetics and its application in mechanical analysis $(\mathrm{a} 1, \mathrm{f}, \mathrm{h}, \mathrm{k})$

3. Knowledge of rigid-body kinematics and its application in mechanical analysis (a1, $\mathrm{f}$, $\mathrm{h}, \mathrm{k})$

4. Knowledge of rigid-body kinetics and its application in mechanical analysis (a $1, \mathrm{f}, \mathrm{h}$, $\mathrm{k})$

5. Knowledge and skills of using engineering computer software for dynamic analysis (a1, d, f, h, k)

6. Knowledge of using computer-aided geometric modeling for dynamic analysis of mechanical systems (a1, b, d, k)

\section{Assessment tool matrix of the learning outcomes}

Tools were defined for assessment of each course learning outcome listed in the above. Table 1 below is a matrix of the assessment tools versus the learning outcomes used for the fall semester of 2003.

Table 1. Assessment tools versus learning outcomes matrix for the dynamics course

\begin{tabular}{|l|c|c|c|c|c|c|}
\hline \multirow{2}{*}{ Assessment Tools } & \multicolumn{6}{|c|}{ Course Learning Outcomes } \\
\cline { 2 - 8 } & 1 & 2 & 3 & 4 & 5 & 6 \\
\hline Homework 1 & $\mathrm{X}$ & & & & & \\
\hline Test 1 & $\mathrm{X}$ & & & & & \\
\hline Test 2 & & $\mathrm{X}$ & & & & \\
\hline Test 3 & & & $\mathrm{X}$ & & & \\
\hline Homework 2 & & & & $\mathrm{X}$ & & \\
\hline Computer Project & & & & & $\mathrm{X}$ & $\mathrm{X}$ \\
\hline Final Exam & $\mathrm{X}$ & $\mathrm{X}$ & $\mathrm{X}$ & $\mathrm{X}$ & & \\
\hline
\end{tabular}

Based on assessment of learning outcomes in the fall 2003 semester, more assessment tools are being used in this fall semester of 2004. (The course was not offered in the spring semester of 2004). 


\section{Assessment with statistical analysis}

Each assessment tool listed in Table 1 is for data collection. The data are analyzed with MiniTab, a statistics tool.

Below is the statistical analysis on the assessment data in the fall semester of 2003.

\section{- Assessment by Homework 1}

Figure 1. MiniTab descriptive statistics of the grade point data of Homework 1

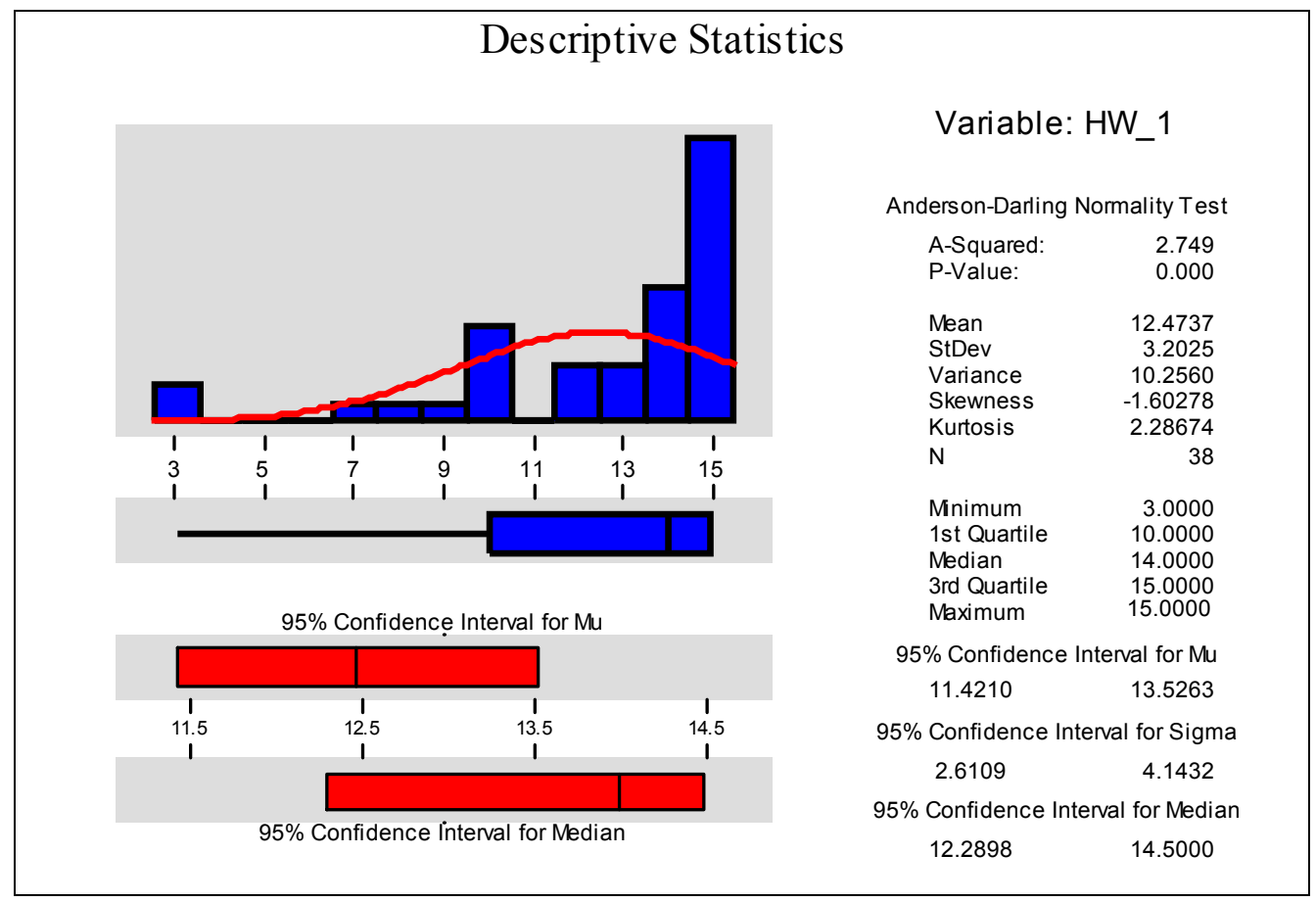

Homework 1 was on application of calculus, which was for course learning outcome 1.

- The full grade of the homework was 15 points.

$\circ$ The graph and the text in Figure 1 indicate that most students did very well on this assignment of using calculus in kinematics. Half the students had scores between the median of 14 points and the maximum of 15 points.

$\circ$ On the other hand, the figure also clearly shows that there were some students who were weak in mathematics. $25 \%$ students had scores between the minimum of 3 points and the $1^{\text {st }}$ quartile of 10 points.

- One of the most significant numbers on the statistics printout is the p-value from Anderson-Darling Normality Test. In statistics ${ }^{3}$, a distribution can be considered approximately normal if the p-value is larger than 0.1 or at least larger than 0.05 . The p-value being almost zero in this homework statistics clearly indicates that the grade point distribution of this homework is far from being normal. 
- Skewness is another measure of normality. It shows the central tendency. In this case, a negative value -1.6 of skewness indicates a left-skewed distribution. As shown in the graph, the entire distribution is on the left of the highest peak.

- Kurtosis shows the relative peakedness or flatness. In this case, a positive value 2.29 of kurtosis indicates a relatively peaked distribution around 15 points, as shown in the figure.

○ The graph, the p-value, the skewness and the kurtosis all state that the grade distribution of this homework was much higher than regular. It normally implies the assignment was not challenging enough. However, our engineering technology students typically are not strong in mathematics and making this easier was meant to motivate them to apply calculus.

\section{- Assessment by Test 1}

Figure 2. MiniTab descriptive statistics of the grade point data of Test 1

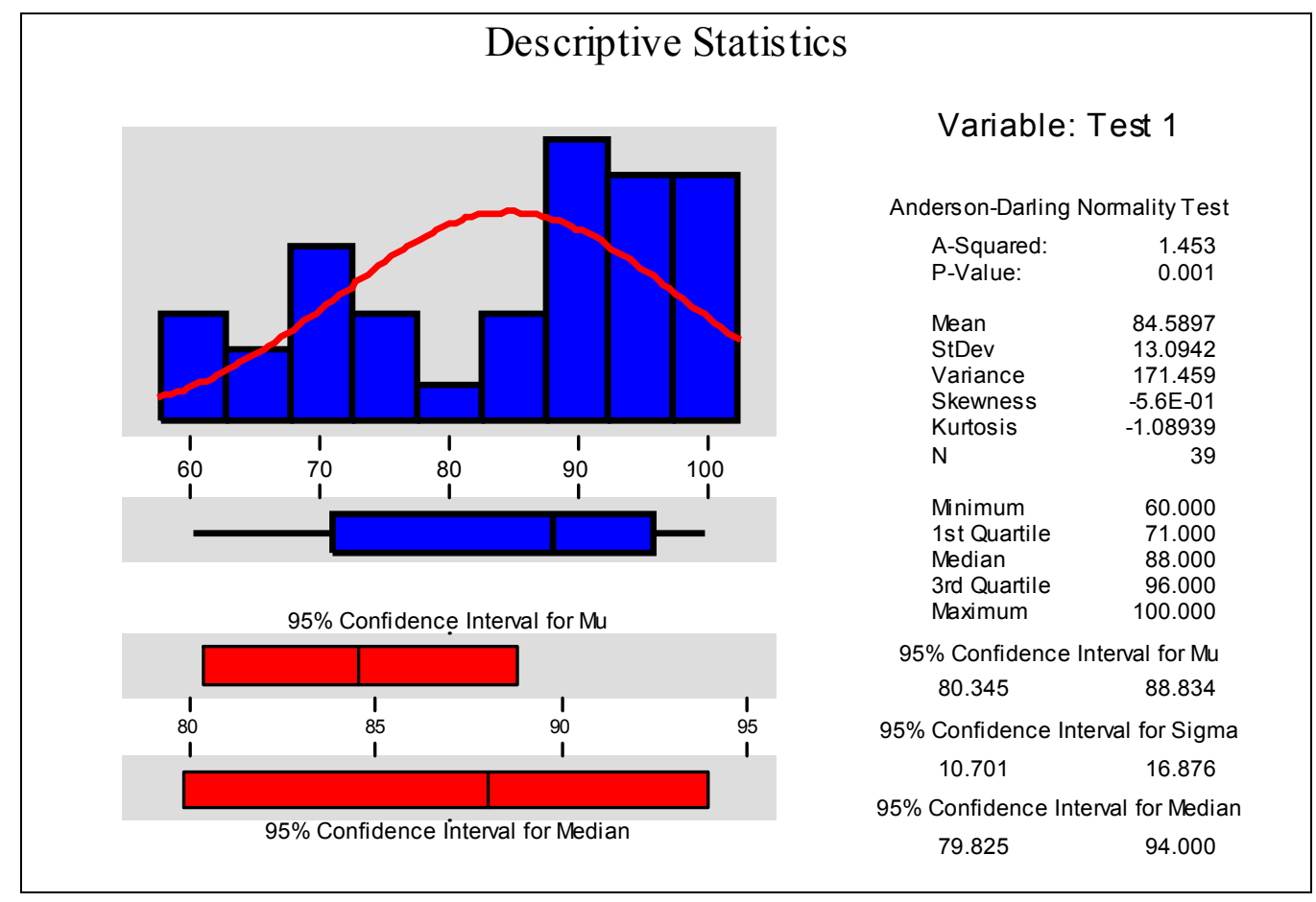

Test 1 was on particle kinematics, which was course learning outcome 1.

- By virtue of the mean of 84 points and the median of 88 points shown in Figure 2, the class appeared to do well on learning outcome 1 assessed on Test 1.

$\circ$ There was a wide spread of the scores while both the mean and the median were very good. The skewness is only -0.56 , close to zero. This should be a healthy situation for a class of thirty nine students. It also showed that the teaching materials and the test problems were at the appropriate level. 
- Assessment by Test 2

Test 2 was on particle kinetics, which was course learning outcome 2.

- As shown in Figure 3 on the next page, the class appeared to do well on learning outcome 2 assessed on this test.

$\circ$ The pretty good mean of 86 points, the median of 89 points, the skewness of -0.5 close to zero and the kurtosis of -0.8 close to zero together indicate a very good distribution. The fact that the students were performing well should indicate that the teaching materials and the test problems were at the appropriate level.

Figure 3. MiniTab descriptive statistics of the grade point data of Test 2

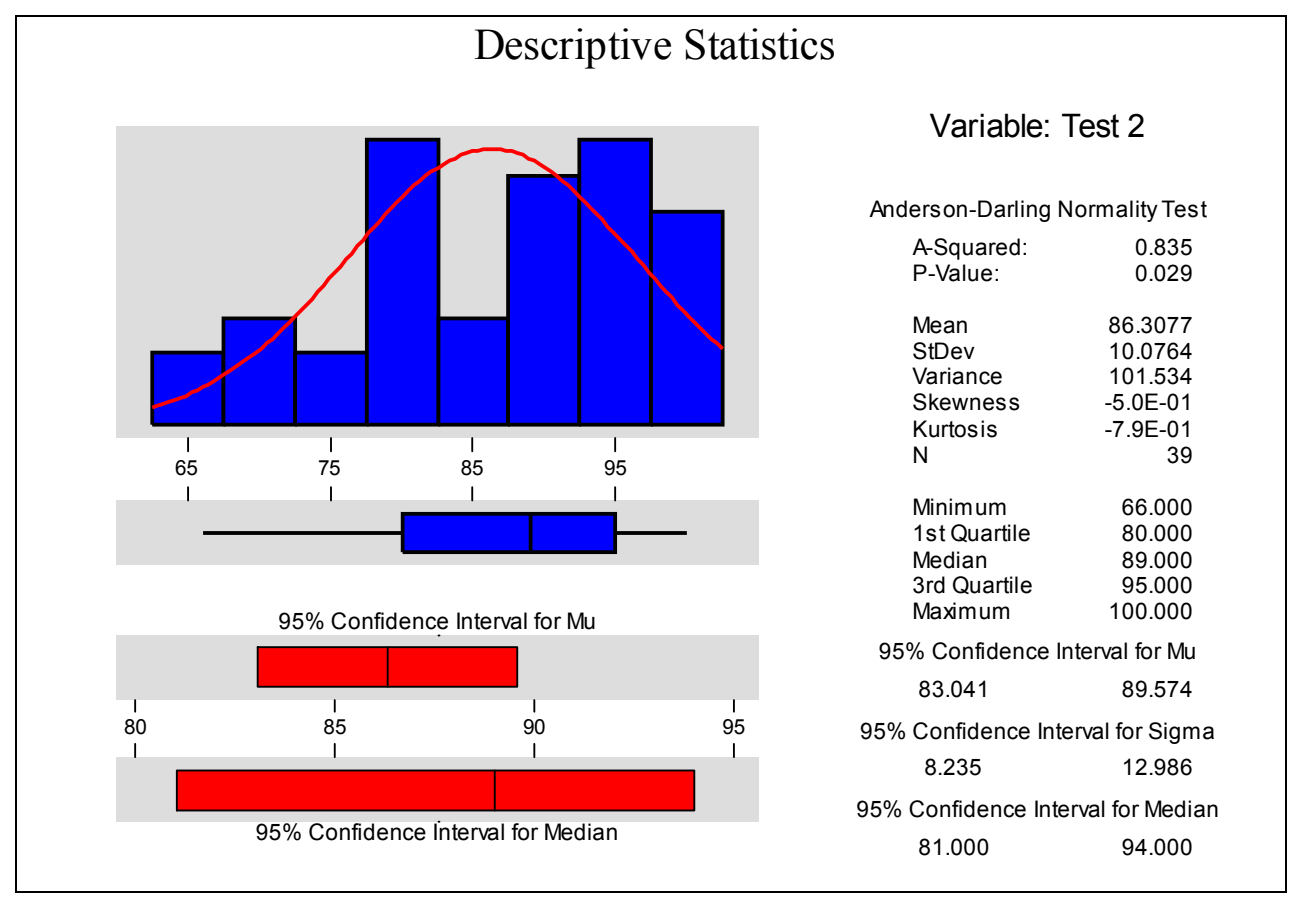




\section{- Assessment by Test 3}

Figure 4. MiniTab descriptive statistics of the grade point data of Test 3

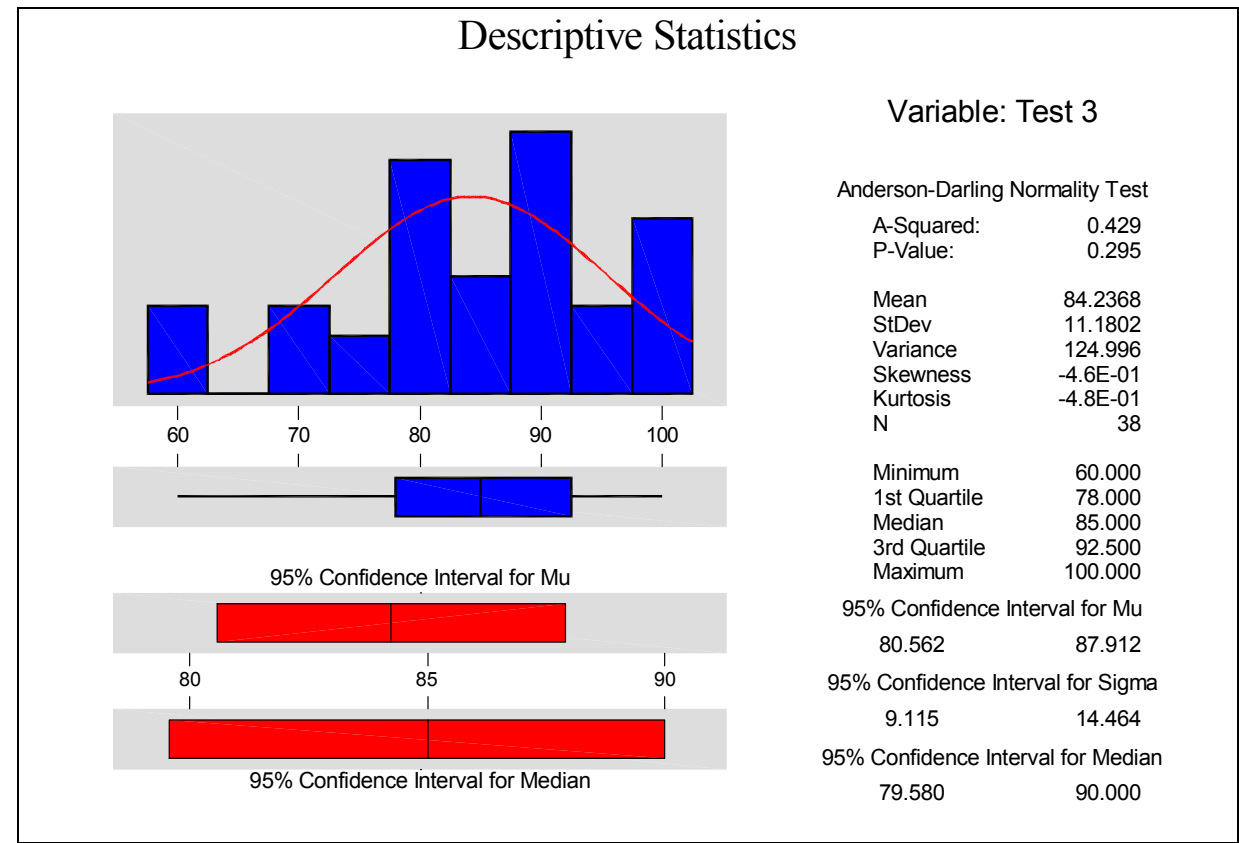

Test 3 was on rigid body kinematics, which was course learning outcome 3.

- The graph in Figure 4 shows the class appeared to do well on learning outcome 3 assessed on this test.

$\circ$ The mean score of 84 , the median score of 85 , the $p$-value of 0.3 , the skewness of -0.5 and the kurtosis of -0.5 together state a very good and healthy grade distribution, which should also indicate that the difficulty level of the course material for the learning outcome and the level of the test were appropriate.

- Study of students' performance on individual problems on the test also told:

- The test problems should have made it clear that students must draw vector polygons in the solutions.

- The students should have been given more exercises on acceleration.

- Since the text book and the solutions manual use vector algebra only, some supplementary handouts on using trigonometry should be planned. 


\section{- Assessment by Homework 2}

Figure 5. MiniTab descriptive statistics of the grade point data of Homework 2

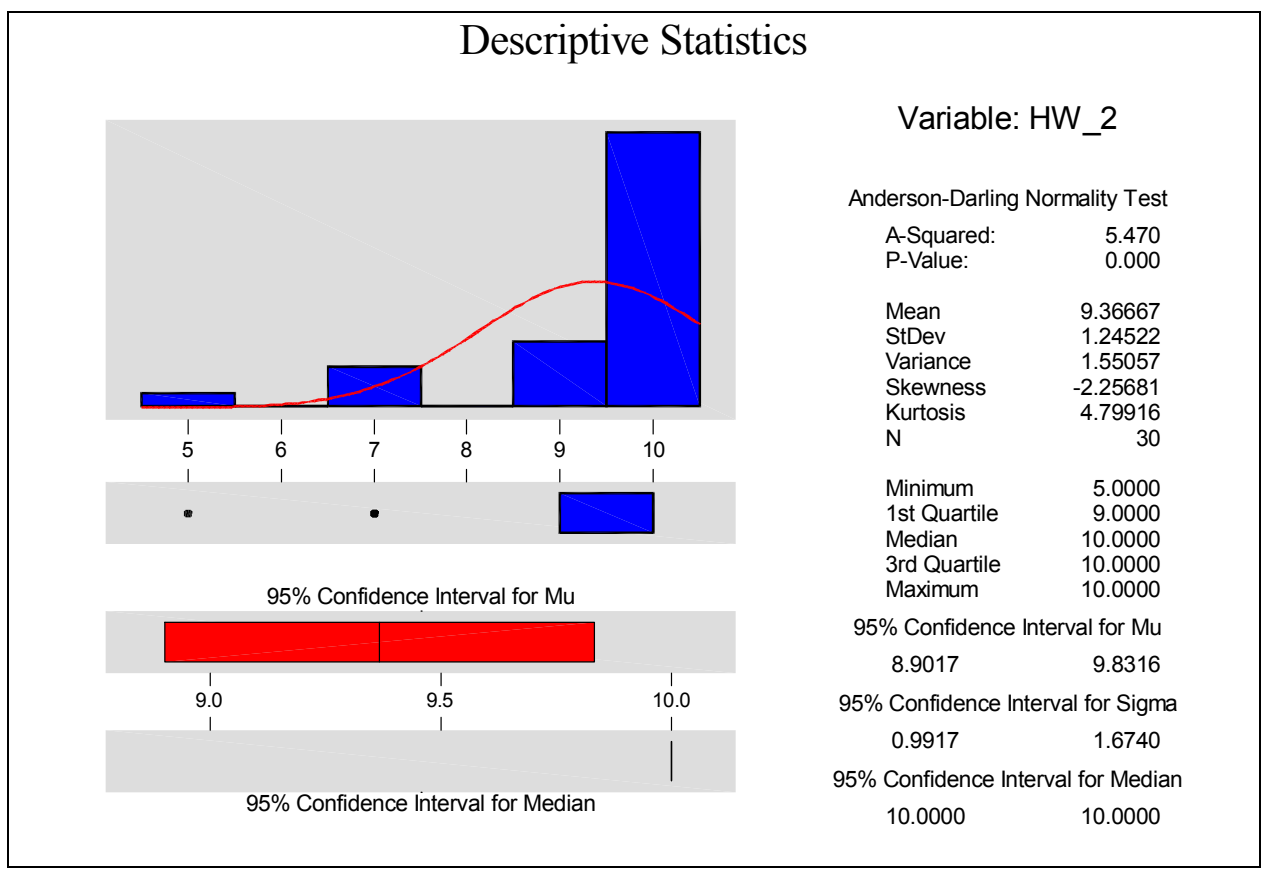

Homework 2 was on impulse and momentum, which was for course learning outcome 4.

- The full grade of the homework was 10 points.

$\circ$ Findings on the learning outcome

- Only thirty students out of the class of thirty nine turned in the homework. The nine students not turning in the work could not demonstrate the learning outcome.

Of the thirty pieces of assignment work turned in,

- Most received high scores of nine or ten. The median score is 9.4 and the mean score is $10.75 \%$ students turning the homework received scores between $1^{\text {st }}$ quartile of 9 point and the maximum of 10 points.

- A few students received low scores as seen as outliers of the distribution. They could not demonstrate the learning outcome.

○ The graph, the $p$ value of almost zero, the skewness of -2.3 and the kurtosis of 4.8 together clearly indicate that the distribution was unhealthy.

- The reason was not that the assignment was not challenging. Rather quite a few students could not complete it independently and copied from others. .

- Reasons for problems with this learning outcome were believed to be:

$\circ$ There were not enough interesting and appropriate example problems for this learning outcome. 
- Class attendance. Without credit given for class attendance, some students did not show up each time and could not learn well.

- Assessment by the Final Exam

Figure 6. MiniTab descriptive statistics of the grade point data of the final exam

\section{Descriptive Statistics}
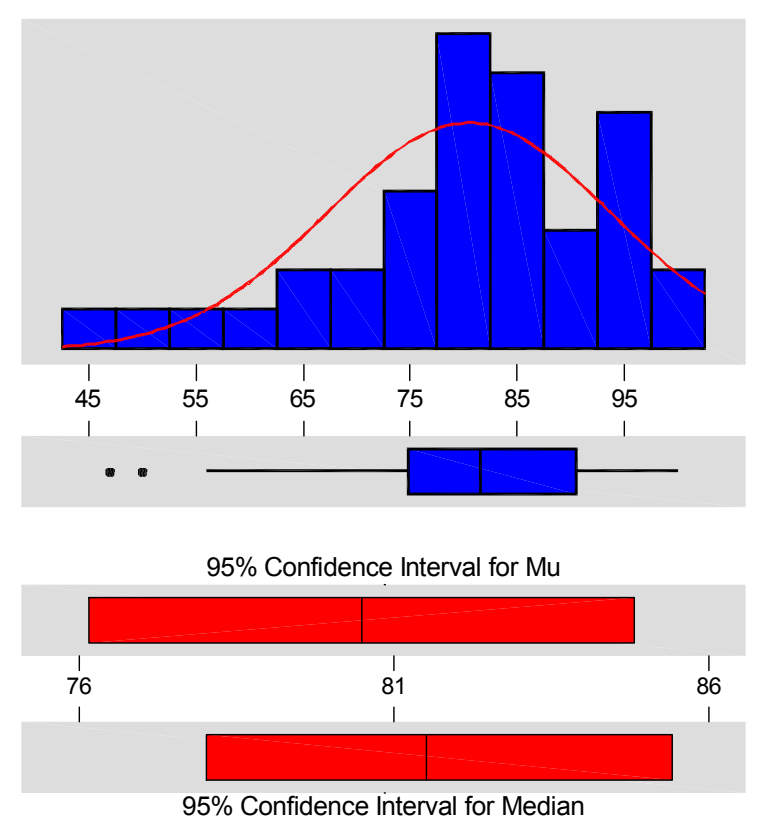

Variable: Final

$\begin{array}{cr}\text { Anderson-Darling } & \text { Normality Test } \\ \text { A-Squared: } & 0.675 \\ \text { P-Value: } & 0.072 \\ \text { Mean } & 80.4737 \\ \text { StDev } & 13.1965 \\ \text { Variance } & 174.148 \\ \text { Skewness } & -8.2 \mathrm{E}-01 \\ \text { Kurtosis } & 0.408621 \\ \text { N } & 38 \\ \text { Minimum } & 47.000 \\ \text { 1st Quartile } & 74.750 \\ \text { Median } & 81.500 \\ \text { 3rd Quartile } & 90.500 \\ \text { Maximum } & 100.000 \\ \text { 95\% Confidence Interval for Mu } \\ \text { 76.136 } & 84.811 \\ \text { 95\% Confidence Interval for Sigma } \\ \text { 10.759 } & 17.073 \\ \text { 95\% Confidence Interval for Median } \\ \text { 78.000 } & 85.420\end{array}$

The final exam was on particle kinematics, particle kinetics, body kinematics and body kinetics, which were course learning outcomes $1,2,3 \& 4$.

- As shown in Figure 6, the median score, the mean score and the spread of the scores together show that the teaching was successful overall and the exam was at an appropriate level.

- There were two students behind the rest of the class.

$\circ$ In the future, class attendance requirement should be implemented more effectively for our students by assigning credit.

- Also I plan to search for a new textbook that, while covering application of dynamics in mechanisms, uses mathematical tools more appropriate to our students.

- Students had more problems with D'Alembert's principle, the last topic of the semester. In the future, no fewer homework assignments should be given in the last week.

- It was also observed that the students had difficulty with both directions and magnitudes of accelerations in rigid body plane motion. More explanation on the directions should be given in the future. 
- About Learning Outcomes 5 and 6

Learning outcomes 5 and 6 are to use computer software and computer geometric modeling for dynamic analysis.

In the semester of fall 2003, demos were given of using Working Model and Visual Nastran 4D by MTS for dynamic simulation of mechanisms. Improvement for these outcomes was needed.

\section{On survey of students' perception of their learning}

Sometimes we use a survey of students' perception of their learning as an assessment tool of course learning outcomes. Such a survey was not performed for the dynamics course in the fall 2003 semester and hence is not included here.

\section{Actions suggested by the assessment results}

Actions suggested by the results of the above stated assessment of the dynamics course in the fall 2003 semester were:

1. Further promoting all students' interest, efforts and ability in this analytical course by

a. Giving more real-life examples

b. More computer simulation

c. More emphasis on critical thinking

d. Awarding credit for class attendance

e. Reviewing math

2. Collecting more homework assignments, especially if some support can be given by the department for grading of this class of forty students.

3. Search for and possible adoption of another textbook that has algebraic approaches for rigid-body kinetics.

The above was reported to the department curriculum committee near the end of the 2003-2004 academic year.

\section{Learning outcomes improvement resulting from the actions}

The improvement actions suggested by the Fall 2003 assessment as listed in the previous section were implemented in the Fall 2004 semester as follow:

○ The course syllabus has been revised to assign credit for attendance.

$\circ$ Problem solving is first on critical thinking and on engineering applications.

- More homework assignments have been collected.

- Instruction and homework on using computer and computer graphics for visualizing engineering dynamics problems have been given.

- While a new textbook has not been located, efforts have been made and will be continued. 
With the above actions, students' learning interest and participation in class activities in this year have obviously been increased from the last year. For example, the completion rates for assignments have substantially increased. Students' learning outcomes have been clearly improved.

\section{Conclusion}

The paper shows that using a statistical software package such as MiniTab for analysis of assessment data allows us to have clear graphical views of the data and to get better understanding of the information contained in the data so that assessment could better serve continuous improvement in accomplishing the program learning outcomes and objectives. The author of this paper has performed assessment analysis with MiniTab for several other courses as well and feels it very beneficial to do so. His interest in this method partially came from his summer experience in applying statistical quality control in industry.

The author of this paper would like to explore the connection between this work and other available methods that deal with interpretation of statistical data related to student testing and possibilities of extending this method to other types of analysis such as faculty index, discrimination index and degree of difficulty.

There are many statistical packages that are Windows-based and have both text outputs and graphical outputs. Their use is rather straightforward and requires no complicated procedure.

Bibliography

1. ABET/TAC Criteria.

2. Indiana University-Purdue University Fort Wayne Assessment Requirements and Guidelines

3. MiniTab 14 Users Guide

\section{Biography}

ZHONGMING (Wilson) LIANG is associate professor of mechanical engineering technology at Indiana UniversityPurdue University Fort Wayne. He has been an ABET/TAC program evaluator for ASME and for SME. 